\title{
Bovine serum albumin protected gold nanozymes as a novel anti-cancer nanodrug for acute T-type lymphoblastic leukemia treatment via effect on the expression of anti-apoptotic genes
}

\author{
Ehsan Vafa@ and Reza Bazargan-Lari
}

\begin{abstract}
In this paper, the bovine serum albumin protected gold nanozymes (BSA-Au nanozymes) were utilized as a novel nanodrug for treatment of acute T-type lymphoblastic leukemia (Jurkat) by production of excessive ROS and effect on the expression of anti-apoptotic genes. The effect of BSA-Au nanozymes on the Bcl-2 expression and survivin in the Jurkat cell line was checked. The results showed that the expression of anti-apoptotic genes was significantly reduced after treatment of the Jurkat cell line with the BSA-Au nanozymes ( $p$-value of 0.001 ) as the potential nanodrug while their expression in the normal PBMC was not affected by the nanodrug. Moreover, the cytotoxic effect of the developed nanodrug on the Jurkat cell line was evaluated which illustrated that survival rate in the studied cell line reaches its minimum value (100\% lethality, $0.0 \%$ survival) after treatment for $48 \mathrm{~h}$. The IC50 for the nanodrug was calculated at $0.05 \mathrm{mM}$ of the developed nanodrug. Overall, the BSA-Au nanozymes can be used as the nanodrug for treatment of T-type lymphoblastic leukemia via reducing the expression of anti-apoptotic genes, increasing the effect of common anticancer drugs such as Adriamycin and ara-C, and consequently increasing the survival of patients with leukemia.
\end{abstract}

Keywords: BSA-Au nanozymes, Anticancer nanodrug, Jurkat, Anti-apoptotic genes, Acute T-type lymphoblastic leukemia

\section{Introduction}

These days, several diseases are affected on human life and cause to decrease life quality. Some of them are cure in short time (such as orthopedic damage [1]) while others may corporate the whole life, like diabetic and blood disease [2, 3]. Acute lymphoblastic leukemia termed as ALL is defined as a type of blood malignancy that is detectable through the accumulation of $\mathrm{B}$ and $\mathrm{T}$ lymphocyte progenitor cells in the bone marrow [4]. ALL is characterized by; (I) the cessation of

\footnotetext{
*Correspondence: rbazarganlari@gmail.com

Department of Materials Science and Engineering, Marvdasht Branch, Islamic Azad University, Marvdasht, Iran
}

puberty, (II) increased proliferation of malignant, and (III) immature lymphoid cells in the blood and bone marrow [5]. On the other hand, ALL is caused by excessive proliferation of $\mathrm{B}$ or $\mathrm{T}$ lymphocyte precursors and accumulation of blast cells in the bone marrow, resulting in the filling of the bone marrow space and finally the suppression of hematopoiesis in the bone marrow, which eventually leads to anemia, thrombocytopenia and becomes neutropenic $[6,7]$. It is proved that ALL occurs in both children and adults, but its peak is at the age of $2-5$ years. Immunophenotypically, ALL is divided into two groups: (I) B-ALL, and (II) T-ALL which $8.0 \%$ of patients of ALL have B-ALL, and others were infected with T-ALL. Although a number of 
commercial drugs are designed and characterized for the treatment of ALL, these chemical anticancer drugs show several harmful side effects [8]. Hence, the recent researches were focused on the production of new drugs with competitive anti-cancer properties, new biomaterials and accelerate the recovery of the disease with that of the synthetic drugs along with fewer side effects [9-11]. However, many studies indicate that, ALL can be control by controlling the expression of Bcl-2 in cancer cells [12-15].

Nowadays, with the fast development of nanoscience, scientists are looking for new methods for the synthesis of nanomaterials with medicinal properties, especially the novel nanodrugs with excellent effectiveness and minimal side effects $[16,17]$. Nanobiotechnology is one of the branches of nanotechnology which has attracted a lot of attention today $[16,18]$. In fact, its mission is the synthesis and characterization of the new nanoparticles using biological methods such as nanoparticles synthesis using the extracts of various plants as reductant [1923], extracts of various microorganisms such as algae as reductant and stabilizer [24-26], and proteins [27, 28] such as bovine serum albumin (BSA) [29] as both reducing and capping agents.

Recently, the medicinal properties of these biosynthesized nanoparticles especially their anti-cancer and antibacterial properties have been widely evaluated for discovering the novel nanodrugs with high biocompatibility [26, 30-33]. For instance, Houshmand et al., developed a magic bullets as a nanocarriers for leukemia treatment and demonstrate that: (i) they may be designed to target leukemic cells selectively; (ii) they invariably enhance bioavailability and blood circulation half-life; (iii) their mode of action is expected to reduce side effects [34].

Among the various nanomaterials, metal-based nanoparticles, especially silver nanoparticles and gold nanoparticles have been widely used in different research fields due to their excellent optical, anti-cancer, and anti-bacterial properties along with high biocompatibility $[35,36]$. So far, the effect of several metal nanoparticles synthesized via different biological methods has been investigated on the different types of cancers [37, 38]. For example, the biosynthesized silver nanoparticles using the extract of Erica carnea as the reductant showed excellent cytotoxic effects on the breast cancer cell line (MCF-7) which can be used as a nanodrug in breast cancer treatment [16]. Moreover, the curcumincoated silver nanoparticles exhibited very excellent effects on the induction of cell death in the A2780 ovarian cancer cell line [9]. There are also reports about the anti-cancer effects of the bio-synthesized silver nanoparticles by Laurencia caspica macroalgae extract on the T47D breast cancer cell line [39], and the silver nanoparticles synthesized with the extract of Aka Lipptus [10].

Studies have shown that gold nanoclusters were introduced as attractive sensors due to their unique fluorescence and catalytic properties [40]. The biosynthesized gold nanoclusters using the protein-assisted method by BSA as both the reducing and capping agents have been widely utilized in analytical and medical chemistry [41, 42]. These nanomaterials which are known as the nanozymes show an enzymatic role in the redox reactions [43]. These catalytic properties of $\mathrm{BSA}-\mathrm{Au}$ nanozymes were the basis for utilizing these nanozymes for several analytical purposes such as colorimetric silver (I) ion detection [44], and dopamine quantification [45] and mercury (II) speciation [46] via nanozyme-based methods.

Although most researches on the BSA-Au nanozymes are focused on their fluorescence and nanozyme-based detection, their potential application in medical science such as neurodegenerative diseases diagnosis [47] was also damned. However, due to the high biocompatibility and excellent enzyme mimic properties of these nanozymes, their potential application for the treatment of cancer can be also considered [45]. In the study, the BSA-Au nanozymes were utilized as a novel potential nanodrug for the treatment of acute T-type lymphoblastic leukemia (Jurkat) via the effect on the expression of anti-apoptotic genes. The effect of BSA$\mathrm{Au}$ nanozymes on the expression of Bcl-2 and survivin in the Jurkat cell line. Moreover, the cytotoxic effect of the developed nanodrug on the Jurkat cell line was evaluated. MTT tests and Real-Time PCR were used to evaluate the viability of cell groups and the expression of anti-apoptotic genes, respectively, and all data were analyzed using SPSS software (version 20).

\section{Experimental}

\section{Synthesis of BSA-Au nanozymes: nanodrug}

BSA-Au nanozymes were synthesized using bovine serum albumin as both reducing and capping agents according to pervious study [48]. Accordingly, $2.5 \mathrm{~mL}$ of $10.0 \mathrm{mM} \mathrm{HAuCl} 4 \cdot 4 \mathrm{H}_{2} \mathrm{O}$ solution was added to $2.5 \mathrm{~mL}$ of $50.0 \mathrm{mg} / \mathrm{mL}$ BSA under stirring, after $2.0 \mathrm{~min}$, $250.0 \mu \mathrm{L}$ of $1.0 \mathrm{M} \mathrm{NaOH}$ was added for the adjustment of $\mathrm{pH}$ of the resulted solution, followed by incubation at $37^{\circ} \mathrm{C}(12 \mathrm{~h})$. After that, the BSA-Au nanozymes were collected, diluted to a final volume of $12.5 \mathrm{~mL}$ in DI water, and stored at solution stored at $4{ }^{\circ} \mathrm{C}$. The molar concentration of BSA-Au nanozymes was calculated based on the initial gold atoms, which is found to be about $1.9 \mathrm{mM}$. 


\section{Evaluation of cytotoxic effects of BSA-Au nanozymes in Jurkat cell line}

The cytotoxic effects of as-synthesized BSA-Au nanozymes in the Jurkat cell line were evaluated by MTT analysis, using the KMTT-500 cell toxicity and viability assessment kit. In a typical MTT assay, the cells first treated with BSA$\mathrm{Au}$ nanozymes upon incubation for about $48.0 \mathrm{~h}$, then cells treated with the BSA-Au nanozymes were shaken upon addition of $100.0 \mu \mathrm{L}$ of the yellow solution of MTT (5.0 min) and afterward re-incubated for $6 \mathrm{~h}$ again. After re-incubation, the well contents of the MTT plate were transferred into the tube tests, followed by centrifugation at ambient temperature, the supernatants were collected and $100.0 \mu \mathrm{L}$ of pure DMSO was introduced to them, followed by transferring all solutions into a new 96-well plate house. The plate was then incubated at ambient temperature under dark for $2 \mathrm{~h}$. After that the ELISA analyzer was utilized to read the absorbance of the probe at $570 \mathrm{~nm}$ and the cell mortality rate termed as CSV was estimated by the following equation;

$$
\operatorname{CSV}(\%)=\left(\mathrm{A}_{\text {control }} / \mathrm{A}_{\text {sample }}\right) \times 100
$$

\section{RNA extraction and synthesis of CDNA}

Regard the extraction of the RNA content of cells, after transferring the contents of each well to a test tube, $1.0 \mathrm{~mL}$ of RL solution was added to the tubes, followed by vortex for cell lysis by incubation at $15-30{ }^{\circ} \mathrm{C}$ for $(5 \mathrm{~min})$. Each tube was then centrifuged at $4{ }^{\circ} \mathrm{C}$ at $12,000 \mathrm{rpm}$ for $5.0 \mathrm{~min}$ and the supernatant was transferred to the Rnase free tube, followed by the addition of $200 \mu \mathrm{L}$ of chloroform and centrifugation at $4{ }^{\circ} \mathrm{C}$ for $12 \mathrm{~min}$ again, the colorless supernatant was collected which contained RNA and $200.0 \mu \mathrm{L}$ ethanol was added to these solutions. The resulted solutions were transferred to a column and centrifuged at $4{ }^{\circ} \mathrm{C}$ at $12,000 \mathrm{rpm}$ for $0.5 \mathrm{~min}$ again, collecting the bottom tube solution and washing by $0.5 \mathrm{~mL}$ wash buffer 1 .

Before cDNA synthesis, the polyadenylation was carried out and the cDNA was immediately synthesized afterward by the addition of $10 \mu \mathrm{L}$ of polyadenylated RNA to each tube, then their dilution to a final volume of $13.0 \mu \mathrm{L}$ with DEPC water, their heating in a dry bath at $75^{\circ} \mathrm{C}$ for $5 \mathrm{~min}$, transferring to an ice bath, and adding 7.0 $\mu \mathrm{L}$ RT enzyme, dNTP mix (100 mM), and RT buffer5 to each tube. Finally, the as-synthesized cDNAs were stored at $-80^{\circ} \mathrm{C}$.

\section{Expression changes of anti-apoptotic genes in Jurkat} and PBMC cell line after treatment with BSA-Au nanozymes The expression changes of the anti-apoptotic genes in the Jurkat and PBMC cell lines were evaluated using RealTime PCR analysis. The tests were performed in the following steps;
I. The template DNA samples were taken out from the -80 freezer and thawed.

II. The main stock was provided for use in the PCR reaction, contain Master Mix (single test equipment), direct and inverse primers (stem cell), DEPC water (Sina gene), and template DNA.

III. $11.5 \mu \mathrm{L}$ from solution (II) was introduced to the $1.0 \mu \mathrm{L}$ of DEPC and $0.5 \mu \mathrm{L}$ of mir-17 primer (NTC sample).

IV. The test tubes were transferred to an ice batch, followed by the addition of $12.0 \mu \mathrm{L}$ from solution (II) and $0.5 \mu \mathrm{L}$ of the desired primer to each tube.

$\mathrm{V}$. After addition of all 40 primers in the tubes, they were placed in the Real time-PCR (ABI Step one plus) and both time and temperature program were set on it. The temperature and time program consisted of one cycle of primary degeneration at $95^{\circ} \mathrm{C}$ and a time of $2.0 \mathrm{~min}$ and 45 cycles of secondary degeneration for $5 \mathrm{~s}$ at $95^{\circ} \mathrm{C}$ and 45 cycles of connection and expansion phase for $30 \mathrm{~s}$ at $60^{\circ} \mathrm{C}$.

\section{Statistical analysis}

To evaluate the obtained data, all data were analyzed using SPSS software version 20. The confidence level for the statistical evaluation of data was considered as $95 \%$ (p-value, 0.05 ). All data were analyzed by both a one-way AONOA and a t-test.

\section{Material and instrumentations for characterization and anti-cancer tests}

An ELISA analyzer (China, model: BIOBASE1000), an Ultrospec 4000 UV-Vis spectrophotometer (Biochrome. Ltd); a pH meter (Metrohm, $827 \mathrm{pH}$ lab); a particle size analyzer (model: SALD-301 V, Japan, Shimadzu) and a transmission electron microscope (Zeiss, model EL10C) were used. It should be mentioned that all materials used in this work were provided from commercial markets in their analytical grades.

\section{Results and discussion}

\section{Morphological characterization of BSA-Au nanozymes}

The morphological characterization of the as-synthesized BSA-Au nanozymes was performed by Transmission electron microscopy. The TEM image of the as-synthesized BSA-nanozymes was shown in Fig. 1. As shown in this figure, the as-synthesized BSA-Au nanozymes have a narrow size distribution from 3.0 to $30.0 \mathrm{~nm}$ with spherical morphology. The mean size of the as-synthesized BSA-Au nanozymes was calculated as $10.0 \mathrm{~nm}$ from the TEM imaging method, showing the synthesis of small size nanozymes upon the utilized experimental method. The properties of the nanomaterials such as optical, 


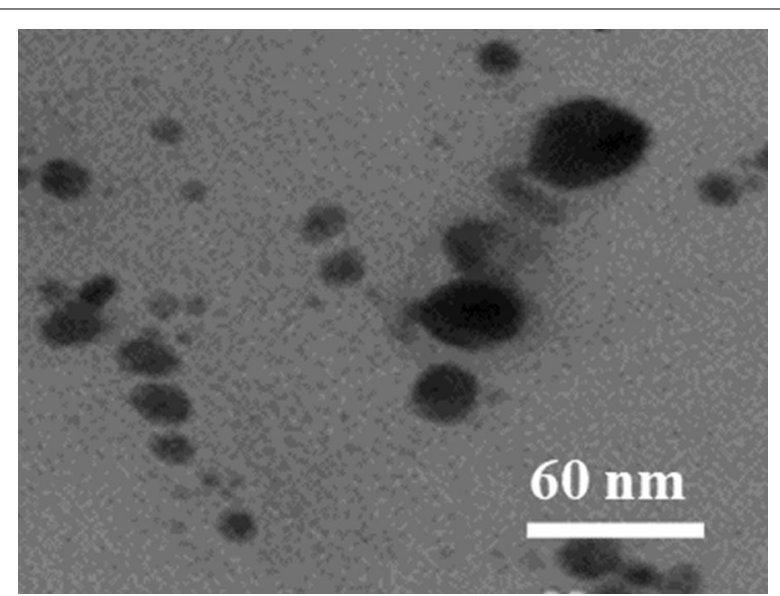

Fig. 1 Morphological characterization of BSA-Au nanozymes by TEM imaging

catalytic, and cytotoxic properties were significantly dependent on their size due to the change in the active sites of nanomaterials by their size variations. The small size points to the higher active sites and consequently the better properties [46].

\section{Size estimation of BSA-Au nanozymes}

Figure 2 demonstrate the data obtain from DLS analysis. DLS analysis are known as the most popular method for nano and micro materials size estimation for exploring more precise on the size of the as-synthesized of nanozymes [49]. As shown in Fig. 2, the as-synthesized BSA-Au nanozymes have a size distribution from 7.0 to $31.0 \mathrm{~nm}$ with a majority distribution of particles in a narrow range from 10.0 to $17.0 \mathrm{~nm}$. The average size of the as-synthesized BSA-Au nanozymes was estimated at about $13.0 \mathrm{~nm}$ form the DLS analysis which is closed

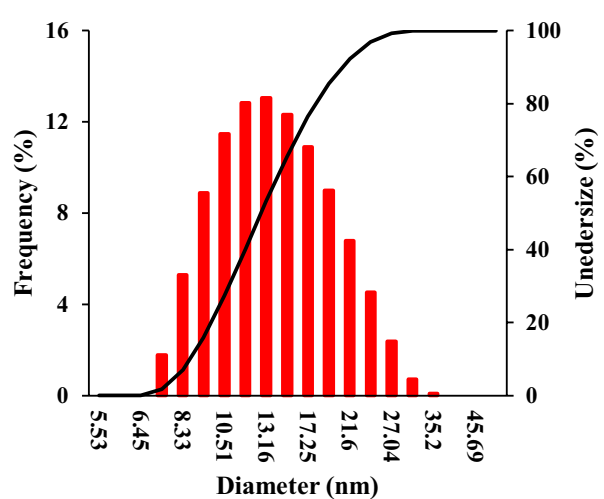

Fig. 2 Estimation of the size distribution of BSA-Au nanozymes by DLS analysis with the average size estimated from the TEM imaging method. The different sizes of the as-synthesized BSA$\mathrm{Au}$ nanozymes can affect their cytotoxic performances toward cancer treatment due to the change in the specific surface area, and the number of active sites with the size variations [50]; however, the majority distribution of particles of the as-synthesized BSA-Au nanozymes are in a narrow range from 10.0 to $17.0 \mathrm{~nm}$ which have the similar potential cytotoxic effects.

\section{Nanozymatic activity of BSA-Au nanozyme}

The nanozymatic activity of the as-synthesized BSAAu nanozymes was checked by the standard assay of 3, 3'-diaminobenzidine (DAB) using the hydrogen peroxide as the reaction starter as reported [51, 52]. To do this, BSA-Au nanozymes $(0.095 \mathrm{mM})$ was added to a solution of DAB $(2.0 \mathrm{mM})$ and hydrogen peroxide $(0.17 \mathrm{M})$, and the solution's color was changed $(\mathrm{pH}$, 7.0) from colorless to brown was considered as the index of nanozymatic activity of the as-synthesized BSA-Au nanozymes. The UV-Visible spectrum of the reaction product was shown in Fig. 3. As shown in this figure, the product of the reaction shows a significant absorbance at $460.0 \mathrm{~nm}$ which is responsible for the production of an indamine polymer during the nanozymatic oxidation of DAB as reported [51,52]. Hence, it can be concluded that the as-synthesized BSA-Au nanozymes showed excellent nanozymatic activity and also showing their successful synthesis.

\section{Evaluation of cytotoxic effects of BSA-Au nanozymes in Jurkat cell line}

For investigating the cytotoxic effects of the assynthesized BSA-Au nanozymes on the Jurkat cells, the MTT tests were carried out after 24, 48, and $72 \mathrm{~h}$ as the treatment time of the cancer cells with

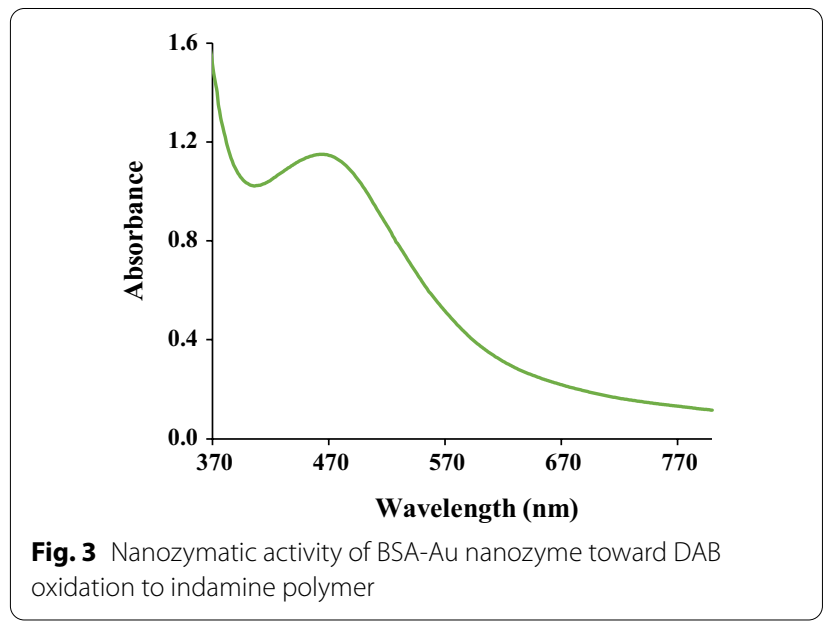


the different dosages of the as-synthesized BSA-Au nanozymes in a concentration range of $0.05-1.9 \mathrm{mM}$ of BSA-Au nanozyme as the anti-cancer nanodrug. The results were shown in Fig. 4. As shown that the CSV percentages for the cancer cells after their treatment with different dosages of the as-synthesized BSA-Au nanozymes were significant differs in all treatment times for the treated Jurkat cell line. Regard, the $24 \mathrm{~h}$ as the treatment time, the as-synthesized BSA-Au nanozymes showed $85.0 \%$ lethality (15.0\% survival) for the treated Jurkat cell line when $1.0 \mathrm{mM}$ of BSA-nanozyme was used and the IC50 of the $\mathrm{Au}$ nanozymes was found to be $0.05 \mathrm{mM}$ for this treatment time. Consider the $48 \mathrm{~h}$ as the treatment time, the as-synthesized BSA-Au nanozymes showed $100.0 \%$ lethality $(0.0 \%$ survival) for the treated Jurkat cell line when $0.3 \mathrm{mM}$ of BSA-nanozyme was used
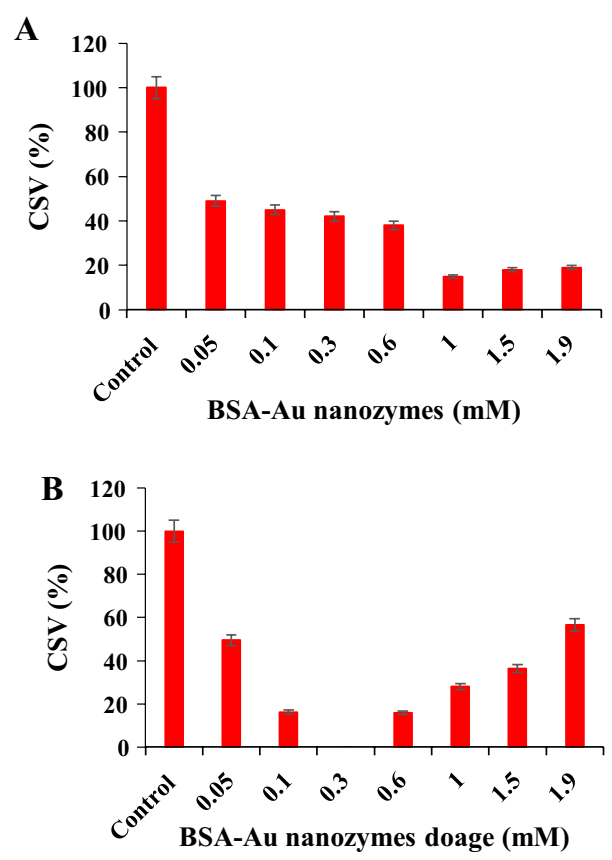

C

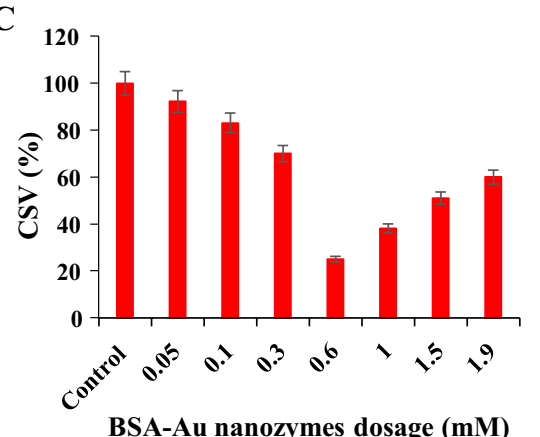

Fig. 4 Evaluation of cytotoxic effects of BSA-Au nanozymes in Jurkat cell line, A 24 h, B 48 h, and C 72 h and the IC50 of the Au nanozymes was found to be $0.05 \mathrm{mM}$ for this treatment time while after $72 \mathrm{~h}$, the as-synthesized BSA-Au nanozymes showed $75.0 \%$ lethality (25.0\% survival) for the treated Jurkat cell line when $0.6 \mathrm{mM}$ of BSA-nanozyme was used and the IC50 of the Au nanozymes was found to be $1.5 \mathrm{mM}$ for this treatment time. Based on the above results, the maximum dosages for the as-synthesized BSA$\mathrm{Au}$ nanozymes for 24,48 and $72 \mathrm{~h}$ of treatment, were found to be $1.0 \mathrm{mM}, 0.3 \mathrm{mM}$, and $0.6 \mathrm{mM}$, respectively. Considering the better IC50 and maximum dosage for the treatment of Jurkat cell line with the as-synthesized BSA-Au nanozymes for $48 \mathrm{~h}$ as the treatment time than $24 \mathrm{~h}$ and $72 \mathrm{~h}$, this time was used at the best treatment time for the cancer treatment using the BSA-Au nanozymes as a novel anti-cancer nanodrug. The results of cytotoxic effects of the BSAAu nanozymes as a novel anti-cancer nanodrug on the Jurkat cell line exhibited that the introduced BSA-Au nanozymes can be utilized as a novel nanopharmaceuticals for acute T-type lymphoblastic leukemia treatment.

Figure 5 indicate the Au-nanozymes and Adriamycin (as a commercial drug) experiments which performed for $48 \mathrm{~h}$, and compared with control and optimum dosage of BSA-Au nanozymes for the Jurkat cell line. As shown in Fig. 5, Au nanozyme showed low lethality of jurkat cell line about 13\% (87\% survival) when $0.3 \mathrm{mM}$ of Au nanozymes was applied. More ever, by increasing the amount of Au nanozymes to $0.6 \mathrm{mM}$, no significant changes were observed in Jurkat cell line lethality ( $80 \%$ survival), while Adriamycin indicate more lethality for treated jurkat cell line. It is observed that in $0.3 \mathrm{mM}$ of Adriamycin the lethality was $56 \%$ ( $44 \%$ survival), and also for $0.6 \mathrm{mM}$ of Adriamycin it is showed extremely reduce to $14 \%$ survival of treated jurkat cell line ( $86 \%$ lethality). It should be noted again that, in the $0.3 \mathrm{mM}$ and $0.6 \mathrm{mM}$ dosages

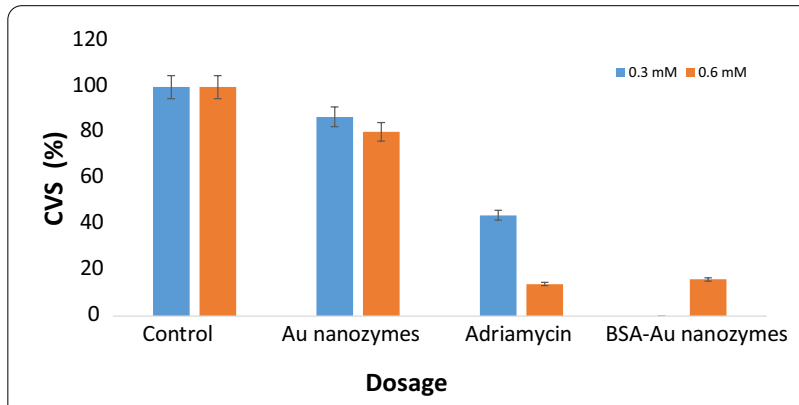

Fig. 5 Results of Jurkat cells viability when expose to BSA-Au nanozymes, Au-nanozymes and Adriamycin with different dosage ( 0.3 and $0.6 \mathrm{mM}$ ) for 48 
of BSA-Au nanozymes, the treated jurkat cell showed $100 \%$ lethality ( $0 \%$ survival) and $84 \%$ lethality (16\% survival) respectively. So, BSA-Au nanozymes have indicated better performance than Au nanozymes and Adriamycin.

\section{Expression changes of anti-apoptotic genes in Jurkat cell line and PBMC after treatment with BSA-Au nanozymes}

The ANOVA results of $\mathrm{Bcl} 2$ expression after the treatment of the Jurkat cell line with the as-synthesized BSAAu nanozymes were shown in Additional file 1: Table S1. As shown, the changes in Bcl-2 expression in the Jurkat cell line after their treatment with the as-synthesized BSA-Au nanozymes were significant with a p-value of 0.001 . In addition, the t-test was performed for comparison with the control. The results showed in Table 1. The data in Table 1 demonstrate that, the expression of the Bcl2 was significantly reduced in the Jurkat cell line after their treatment with the as-synthesized BSA-Au nanozymes as the nanodrug compared with the control. Moreover, the ANOVA results of survivin expression after the treatment of the Jurkat cell line by the as-synthesized BSA-Au nanozymes were shown in Additional file 1: Table S2, which is indicate that, the changes in survivin expression in the Jurkat cell line after their treatment with the as-synthesized BSA-Au nanozymes were significant with a p-value of 0.003 . In addition, the $\mathrm{t}$-test was performed for comparison with the control. The results showed in Table 2, compared to the control, the BSA-Au nanozymes-Max group had a decrease in expression of 0.01 , which was statistically significant $(\mathrm{p}=0.005)$.

It is reported that $\mathrm{Bcl} 2$ can inhibit the activity of proapoptotic proteins, increase the cell viability [53, 54], and prevent the apoptosis $[55,56]$, hence, the theory of $\mathrm{Bcl} 2$ tumorigenic potential was evaluated based on the increase in its expression in several types of cancers [57]. On the other hand, the Bcl2 expression in the cancer cells was found to be higher than the normal cells. Hence, the $\mathrm{Bcl} 2$ expression changes can be considered as a biomarker for the diagnosis of cancer in its early steps in the patients with family history. In this regard, the $\mathrm{Bcl} 2$ expression changes were investigated in breast cancer [58], esophageal cancer [59], and thyroid medullary carcinoma [60]. As reported [61], the higher level for the $\mathrm{Bcl} 2$ expression in the cancer cells caused to the lower life expectancy of patients with cancer, moreover, the toxicity of Adriamycin and ara-C on the cancer cells was reduced when the $\mathrm{Bcl} 2$ expression was increased in the cancer cells, causing low recovery rate of the patients with cancer [62]. Based on the above considerations, the researchers recommended that the effects of cytotoxic drugs on the leukemic cells can significantly increase via reduction of the $\mathrm{Bcl} 2$ expression in the cancer cells, leading to an increase in the survival rate and recovery of patients [62].

Expect the $\mathrm{Bcl} 2$, survivin as a new member of the apoptosis inhibitory proteins (IAP) family can increase the cell viability, and prevent the apoptosis. This gene shows a distinctive expression in the tumor cells, unlike normal cells. Hence, it was known as the fourth major trans-Cryptome in tumors [63]. The production and expression of survivin were increased in many human tumors and embryonic tissues. Therefore, the researchers recommended that cancer cells can be reduced by reducing the survivin expression in

Table 1 T-test results for Bcl2 expression on Jurkat cell line after treatment with BSA-Au nanozymes

\begin{tabular}{|c|c|c|c|c|c|}
\hline t-test & $\begin{array}{l}\text { Mean diff } \\
\text { Fold change }(\log 2) \pm \text { SEM }\end{array}$ & Fold change & $95.0 \% \mathrm{Cl}$ of diff & Result & $p$-value \\
\hline $\begin{array}{l}\text { Jur-BSA-Au nanozymes } 50 \\
\text { vs. Jur control }\end{array}$ & $-11.7 \pm 2.3$ & 0.0006 & -15.0 to -6.3 & Down & 0.0007 \\
\hline $\begin{array}{l}\text { Jur- Au nanozymes vs. Jur } \\
\text { control }\end{array}$ & $-12.0 \pm 2.2$ & 0.0004 & -15.4 to -6.6 & Down & 0.0005 \\
\hline
\end{tabular}

Table 2 T-test results for survivin expression on Jurkat cell line after treatment with BSA-Au nanozymes

\begin{tabular}{|c|c|c|c|c|c|}
\hline t-test & $\begin{array}{l}\text { Mean diff } \\
\text { Fold change }(\log 2) \pm S E M\end{array}$ & Fold change & $95.0 \% \mathrm{Cl}$ of diff & Result & $p$-value \\
\hline $\begin{array}{l}\text { Jur- BSA-Au nanozymes } \\
\text { Max vs. Jur control }\end{array}$ & $-6.6 \pm 1.5$ & 0.01 & -10.75 to -2.48 & Down & 0.005 \\
\hline $\begin{array}{l}\text { Jur- BSA-Au nanozymes } \\
50 \text { vs. Jur control }\end{array}$ & $1.6 \pm 2.3$ & 3.09 & -2.50 to 5.76 & - & 0.42 \\
\hline
\end{tabular}


the cancer cells because this reduction, increases the apoptosis of the cancer cells [64].

In the case of BSA-Au nanozymes, based on the studies reviewed, variety of in vitro and in vivo studies show good performance of bovine serum albumin as the drug carrier, surface modification agent and biomimetic template in cancer therapy $[65,66]$ and when it combined with Au nanoparticle cause excessive production of ROS which can damage cancer cells during oxidize the mitochondrial membrane disrupting and its potential and leaking more superoxide anions into the cytosol which can in turn be converted into $\mathrm{H}_{2} \mathrm{O}_{2}$ molecules. These further diffuse across membranes and damage RNA and as results, decrease $\mathrm{Bcl}-2$ expression. It should be mentioned that $\mathrm{Bcl}-2$ maintain mitochondrial integrity [67-69].

As mentioned above, Bcl-2 inhibits apoptosis by increasing the time-to-death and intrinsic cell-to-cell variations in the mitochondrial pathway of cell death [70]. Thus, considering the significant decrease in expression of both survivin and Bcl-2 expression in the Jurkat cell line after treatment with the BSA-Au nanozymes, it can be deduced that the as-synthesized BSA-Au nanozymes (the introduced nanodrug) can reduce the number of cancer cells through stopping in the cell cycle and controlling its unbridled proliferation. Moreover, the BSA-Au nanozymes can be used along with the common drugs such as Adriamycin and ara- $\mathrm{C}$ to increase the survival of patients with leukemia via increasing the cytotoxic effects of drugs via reduction of the expression of the anti-apoptotic genes in the cancer cells and also enhance the radiosensitization by causing cell cycle disruption and inducing apoptosis. Hence, the use of the as-synthesized BSA-Au nanozymes can be considered as a novel nanodrug for the treatment of patients infected with ALL.

For evaluation of the ability of the BSA-Au nanozymes as an anti-cancer drug, it is necessary that their effects were evaluated on the normal cells. The drug with minimal effects on the normal cells and maximal effects on the cancer cells can be considered as a high powerful drug for cancer treatment. Hence, the expression changes of anti-apoptotic genes in PBMC after treatment with BSA-Au nanozymes were checked. The results of the treatment of PBMC by BSA$\mathrm{Au}$ nanozymes showed that $\mathrm{Bcl}-2$ expression changes in the PBMC (Additional file 1: Table S3) were not significant ( $\mathrm{p}$-value, 0.990). Moreover, the t-test showed that in the PBMC, the changes of Bcl-2 are not significant (Table 3).

Regard, the survivin expression in PBMC, the results showed that according to the one-way ANOVA test (Additional file 1: Table S4), the survivin expression in PBMC was not changed significantly between the studied groups $(p=0.604)$. In comparison with the control group based on the t-test (Table 4), in the PBMC, the changes are not significant. Based on the above results, it can be concluded that the BSA-Au-nanozymes show no significant effect on the normal cells due to their high biocompatibility as reported [71] while they significantly reduce the expression of anti-apoptotic genes in the cancer cells. Hence, the as-synthesized BSA-Au nanozymes as a potential novel nanodrug can increase the survival of patients with leukemia. Figure 6 indicate the expression changes of anti-apoptotic genes in Jurkat cell line and PBMC after treatment with BSA-Au nanozymes.

Table 3 T-test results for Bcl2 expression on PBMC after treatment with BSA-Au nanozymes

\begin{tabular}{|c|c|c|c|c|c|}
\hline t-test & $\begin{array}{l}\text { Mean diff } \\
\text { Fold change }(\log 2) \pm \text { SEM }\end{array}$ & Fold change & $95.0 \% \mathrm{Cl}$ of diff & Result & $p$-value \\
\hline $\begin{array}{l}\text { PBMC-BSA-Au nanozymes } \\
50 \text { vs. PBMC Control }\end{array}$ & $1.7 \pm 5.0$ & 3.4 & -6.8 to 10.3 & Not significant & 0.69 \\
\hline $\begin{array}{l}\text { PBMC-BSA-Au nanozymes } \\
\text { Max vs. PBMC Control }\end{array}$ & $0.4 \pm 4.0$ & 1.3 & -8.1 to 9.0 & Not significant & 0.95 \\
\hline
\end{tabular}

Table 4 T-test results for survivin expression in PBMC after treatment with BSA-Au nanozymes

\begin{tabular}{|c|c|c|c|c|c|}
\hline t-test & $\begin{array}{l}\text { Mean diff } \\
\text { Fold change }(\log 2) \pm S E M\end{array}$ & Fold change & $95.0 \% \mathrm{Cl}$ of diff & Result & $p$-value \\
\hline $\begin{array}{l}\text { PBMC-BSA-Au nanozymes } \\
50 \text { vs. PBMC control }\end{array}$ & $-1.7 \pm 2.6$ & 0.30 & -7.7 to 4.3 & Not significant & 0.56 \\
\hline $\begin{array}{l}\text { PBMC- BSA-Au } \\
\text { nanozymes Max vs. PBMC } \\
\text { control }\end{array}$ & $-1.2 \pm 2.7$ & 0.48 & -7.2 to 4.9 & Not significant & 0.69 \\
\hline
\end{tabular}



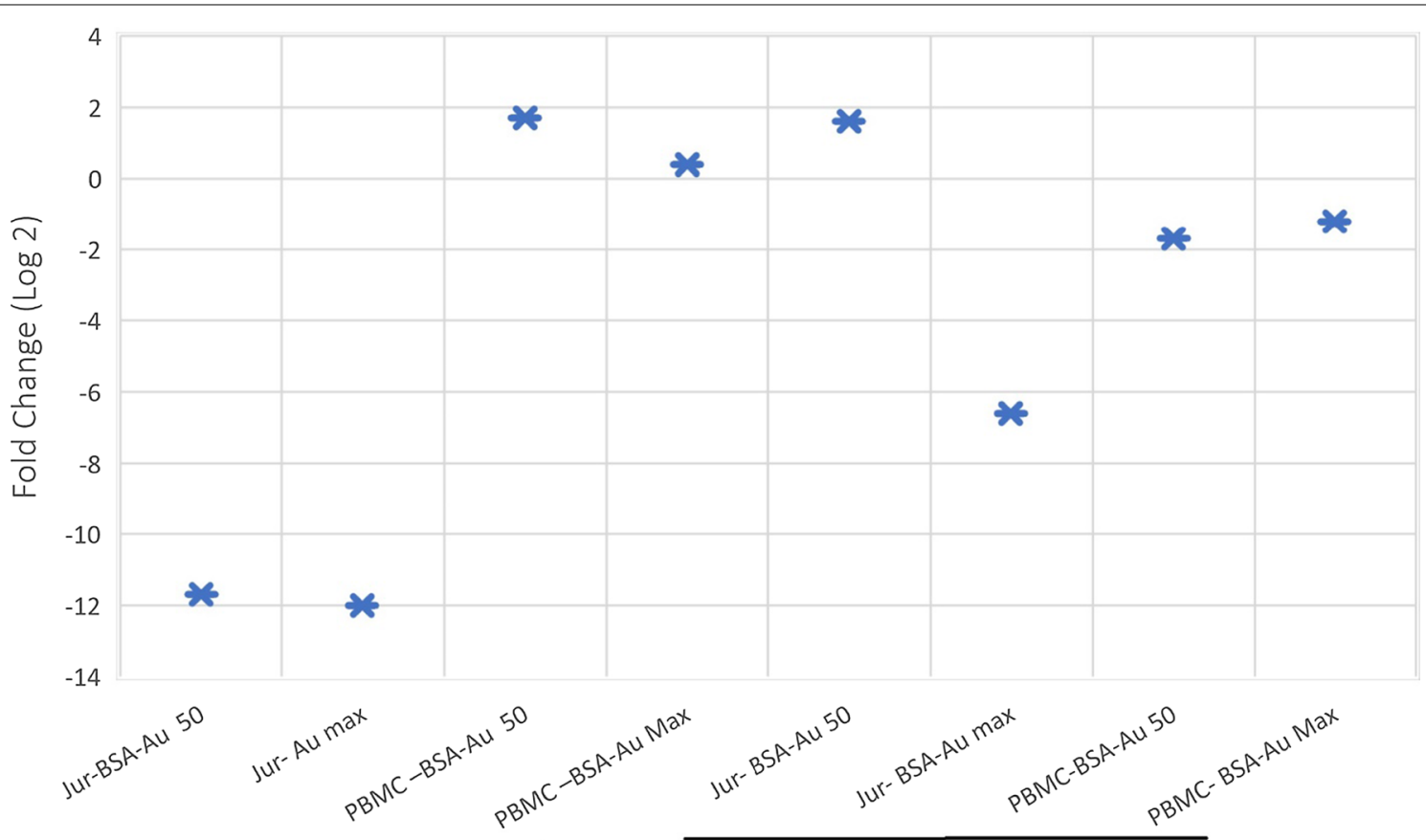

Bcl2

\section{Survivin}

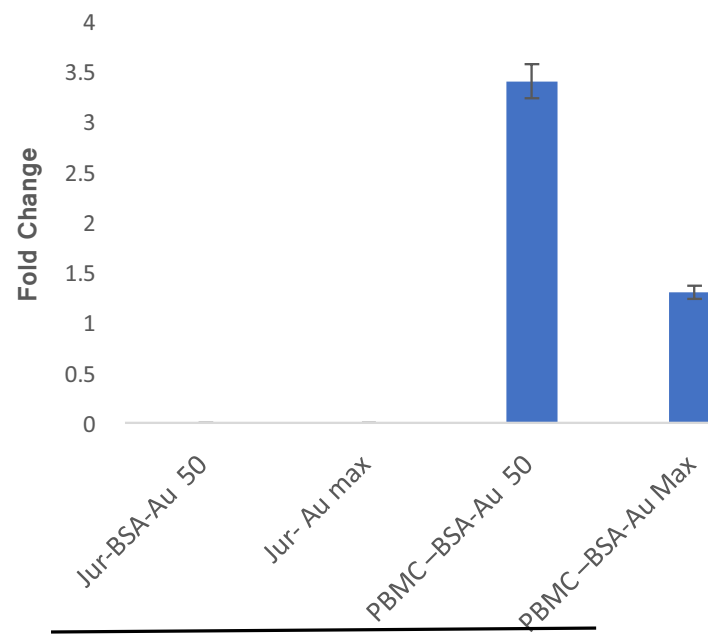

Bcl-2
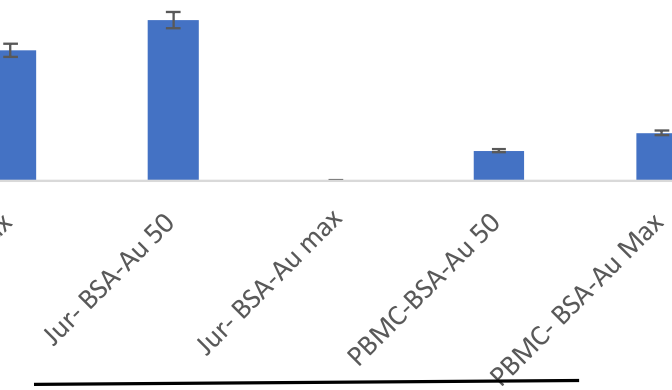

Survivin

Fig. 6 Expression changes of anti-apoptotic genes in Jurkat cell line and PBMC after treatment with BSA-Au nanozymes 


\section{Supplementary Information}

The online version contains supplementary material available at https://doi. org/10.1186/s13765-021-00659-6.

Additional file 1: Table S1. ANOVA analysis for Bcl2 expression on Jurkat cell line after treatment with BSA-Au nanozymes. Table S2. ANOVA analysis for survivin expression on Jurkat cell line after treatment with BSA-Au nanozymes. Table S3. ANOVA analysis for BCl2 expression on PBMC after treatment with BSA-Au nanozymes. Table S4. ANOVA analysis for survivin expression in PBMC after treatment with BSA-Au nanozymes.

\section{Acknowledgements}

We would like to thank all the natural and legal persons who have been involved in the success of this study.

\section{Authors' contributions}

All authors read and approved the final manuscript.

\section{Funding}

No funding was received.

\section{Availability of data and materials}

The datasets used during the current study are available from the corresponding author on reasonable request.

\section{Declarations}

\section{Competing interests}

The authors declare that they have no known competing financial interests or personal relationships that could have appeared to influence the work reported in this paper.

Received: 26 August 2021 Accepted: 4 December 2021 Published online: 17 December 2021

\section{References}

1. Vafa E, Bazargan-Lari R, Bahrololoom ME (2021) Electrophoretic deposition of polyvinyl alcohol/natural chitosan/bioactive glass composite coatings on 316 L stainless steel for biomedical application. Prog Org Coat 151:106059

2. Sullivan G, Wells KB, Leake B (1991) Quality of life of seriously mentally ill persons in Mississippi. Psychiatr Serv 42:752-755

3. Meeske K, Katz ER, Palmer SN, Burwinkle T, Varni JW (2004) Parent proxyreported health-related quality of life and fatigue in pediatric patients diagnosed with brain tumors and acute lymphoblastic leukemia. Cancer 101:2116-2125

4. Liu Y, Easton J, Shao Y, Maciaszek J, Wang Z, Wilkinson MR et al (2017) The genomic landscape of pediatric and young adult T-lineage acute lymphoblastic leukemia. Nat Genet 49:1211

5. Alpdogan O, Schmaltz C, Muriglan SJ, Kappel BJ, Perales M-A, Rotolo JA et al (2001) Administration of interleukin-7 after allogeneic bone marrow transplantation improves immune reconstitution without aggravating graft-versus-host disease. Blood J Am Soc Hematol 98:2256-2265

6. Hendrikx J (1997) Homing on Track: rare cell detection methods to study homing of leukemic and normal hematopoietic stem cells

7. van EwijkW (1977) Microenvironments of T and B lymphocytes: a lightand electromicroscopic study

8. Hoffbrand AV, Higgs DR, Keeling DM, Mehta AB (2016) Postgraduate haematology. Wiley, Hoboken

9. Ramezani T, Nabiun I, Namvar F (2016) Anti-cancerous effects of silver nanoparticles coated with curcmin on A2780 ovarian cancerous cells. J Cell Tissue 7:313-322

10. Rashmezad MA, Asgary EA, Tafvizi F, Shandiz SAS, Mirzaie A (2015) Comparative study on cytotoxicity effect of biological and commercial synthesized nanosilver on human gastric carcinoma and normal lung fibroblast cell lines. Tehran Univ Med J 72:799-807
11. Vafa E, Bazargan-Lari R, Bahrololoom ME (2021) Synthesis of $45 S 5$ bioactive glass-ceramic using the sol-gel method, catalyzed by low concentration acetic acid extracted from homemade vinegar. J Market Res 10:1427-1436

12. Kirkin $V$, Joos S, Zörnig M (2004) The role of Bcl-2 family members in tumorigenesis. Biochim Biophys Acta BBA Mol Cell Res 1644:229-249

13. Borner C (2003) The BCl-2 protein family: sensors and checkpoints for lifeor-death decisions. Mol Immunol 39:615-647

14. Sattler M, Liang H, Nettesheim D, Meadows RP, Harlan JE, Eberstadt $M$ et al (1997) Structure of BCl-xL-Bak peptide complex: recognition between regulators of apoptosis. Science 275:983-986

15. Opferman JT, Kothari A (2018) Anti-apoptotic BCL-2 family members in development. Cell Death Differ 25:37-45

16. Asiabar FG, Mirzaie A, Arasteh J (2019) Antibacterial and cytotoxicity of synthesized silver nanoparticles using Erica carnea extract on breast cancer cell line (MCF-7) and analysis of its apoptotic effects. Razi J Med Sci 26:84-94

17. Asadi L, Shirvalilou S, Khoee S, Khoei S (2018) Cytotoxic effect of 5-fluorouracil-loaded polymer-coated magnetite nanographene oxide combined with radiofrequency. Anti-Cancer Agents Med Chem (AntiCancer Agents) 18:1148-1155

18. Salata OV (2004) Applications of nanoparticles in biology and medicine. J Nanobiotechnol 2:1-6

19. Joshi S, Singh H, Sharma S, Barman P, Saini A, Verma G (2021) Synthesis and characterization of graphene oxide-bovine serum albumin conjugate membrane for adsorptive removal of Cobalt (II) from water. Int J Environ Sci Technol 18:3915-3928

20. Mittal AK, Chisti Y, Banerjee UC (2013) Synthesis of metallic nanoparticles using plant extracts. Biotechnol Adv 31:346-356

21. Kharissova OV, Dias HR, Kharisov BI, Pérez BO, Pérez VMJ (2013) The greener synthesis of nanoparticles. Trends Biotechnol 31:240-248

22. Elia P, Zach R, Hazan S, Kolusheva S, Porat ZE, Zeiri Y (2014) Green synthesis of gold nanoparticles using plant extracts as reducing agents. Int J Nanomed 9:4007

23. Makarov V, Love A, Sinitsyna O, Makarova S, Yaminsky I, Taliansky M et al (2014) "Green" nanotechnologies: synthesis of metal nanoparticles using plants. Acta Naturae (англоязычная версия) 6:35-44

24. Singaravelu G, Arockiamary J, Kumar VG, Govindaraju K (2007) A novel extracellular synthesis of monodisperse gold nanoparticles using marine alga, Sargassum wightii Greville. Colloids Surf, B 57:97-101

25. Asmathunisha N, Kathiresan K (2013) A review on biosynthesis of nanoparticles by marine organisms. Colloids Surf, B 103:283-287

26. Khan AU, Khan M, Malik N, Cho MH, Khan MM (2019) Recent progress of algae and blue-green algae-assisted synthesis of gold nanoparticles for various applications. Bioprocess Biosyst Eng 42:1-15

27. Zhong Y, Peng F, Wei X, Zhou Y, Wang J, Jiang X et al (2012) Microwave-assisted synthesis of biofunctional and fluorescent silicon nanoparticles using proteins as hydrophilic ligands. Angew Chem 124:8613-8617

28. Yamashita I, Hayashi J, Hara M (2004) Bio-template synthesis of uniform CdSe nanoparticles using cage-shaped protein, apoferritin. Chem Lett 33:1158-1159

29. Mendes TV, Franqui LS, Santos MG, Wisniewski C, Figueiredo EC (2020) Synthesis and characterization of a new magnetic restricted access molecularly imprinted polymer for biological sample preparation. Mater Today Commun 24:101002

30. Gul AR, Shaheen F, Rafique R, Bal J, Waseem S, Park TJ (2020) Grassmediated biogenic synthesis of silver nanoparticles and their drug delivery evaluation: a biocompatible anti-cancer therapy. Chem Eng J 407:127202

31. Sulaiman GM, Waheeb HM, Jabir MS, Khazaal SH, Dewir YH, Naidoo Y (2020) Hesperidin loaded on gold nanoparticles as a drug delivery system for a successful biocompatible, anti-cancer, anti-inflammatory and phagocytosis inducer model. Sci Rep 10:1-16

32. Malmir S, Karbalaei A, Pourmadadi M, Hamedi J, Yazdian F, Navaee M (2020) Antibacterial properties of a bacterial cellulose CQD-TiO2 nanocomposite. Carbohydr Polymers 234:115835

33. Asadi L, Shirvalilou S, Khoee S, Khoei S (2018) Cytotoxic effect of 5-fluorouracil-loaded polymer-coated magnetite nanographene oxide combined with radiofrequency. Anti-Cancer Agents Med Chem (Former Curr Med Chem-Anti-Cancer Agents) 18:1148-1155 
34. Houshmand M, Garello F, Circosta P, Stefania R, Aime S, Saglio G et al (2020) Nanocarriers as magic bullets in the treatment of leukemia. Nanomaterials 10:276

35. Majdalawieh A, Kanan MC, El-Kadri O, Kanan SM (2014) Recent advances in gold and silver nanoparticles: synthesis and applications. J Nanosci Nanotechnol 14:4757-4780

36. Sánchez-López E, Gomes D, Esteruelas G, Bonilla L, Lopez-Machado AL, Galindo R et al (2020) Metal-based nanoparticles as antimicrobial agents: an overview. Nanomaterials 10:292

37. Hashemi Z, Mortazavi-Derazkola S, Biparva P, Goli H, Sadeghian F, Kardan M et al (2021) Green synthesized silver nanoparticles using feijoa sellowiana leaf extract, evaluation of their antibacterial, anticancer and antioxidant activities. Iran J Pharm Res 19:306-320

38. Ghooshchian M, Khodarahmi P, Tafvizi F (2016) Expression of apoptosisrelated genes bcl-2 and bax in rat brain hippocampus, followed by intraperitoneal injection of nanosilver. ISMJ 19:185-193

39. Salehzadeh A, Sadat Shandiz A, Naeemi AS (2018) Cytotoxicity effectiveness of biosynthesized silver nanoparticles on breast cancer T47D cell line, using macro algae Laurencia caspica extract. Sci J Ilam Univ Med Sci 26:52-61

40. Cao D, Fan J, Qiu J, Tu Y, Yan J (2013) Masking method for improving selectivity of gold nanoclusters in fluorescence determination of mercury and copperions. Biosens Bioelectron 42:47-50

41. Wong XY, Quesada-González D, Manickam S, New SY, Muthoosamy K, Merkoçi A (2021) Integrating gold nanoclusters, folic acid and reduced graphene oxide for nanosensing of glutathione based on "turn-off" fluorescence. Sci Rep 11:1-12

42. Hemmateenejad B, Shakerizadeh-shirazi F, Samari F (2014) BSA-modified gold nanoclusters for sensing of folic acid. Sens Actuators B Chem 199:42-46

43. Wu J, Wang X, Wang Q, Lou Z, Li S, Zhu Y et al (2019) Nanomaterials with enzyme-like characteristics (nanozymes): next-generation artificial enzymes (II). Chem Soc Rev 48:1004-1076

44. Zhang M, Le H-N, Jiang X-Q, Guo S-M, Yu H-J, Ye B-C (2013) A ratiometric fluorescent probe for sensitive, selective and reversible detection of copper (II) based on riboflavin-stabilized gold nanoclusters. Talanta 117:399-404

45. Chang Y, Zhang Z, Hao J, Yang W, Tang J (2016) BSA-stabilized Au clusters as peroxidase mimetic for colorimetric detection of Ag+. Sens Actuators, B Chem 232:692-697

46. Li R, Zhen M, Guan M, Chen D, Zhang G, Ge J et al (2013) A novel glucose colorimetric sensor based on intrinsic peroxidase-like activity of C60-carboxyfullerenes. Biosens Bioelectron 47:502-507

47. Jain V, Bhagat S, Singh S (2021) Bovine serum albumin decorated gold nanoclusters: a fluorescence-based nanoprobe for detection of intracellular hydrogen peroxide. Sens Actuators B Chem 327:128886

48. Jangi SRH, Akhond M, Absalan G (2020) A novel selective and sensitive multinanozyme colorimetric method for glutathione detection by using an indamine polymer. Anal Chim Acta 1127:1-8

49. Hoo CM, Starostin N, West P, Mecartney ML (2008) A comparison of atomic force microscopy (AFM) and dynamic light scattering (DLS) methods to characterize nanoparticle size distributions. J Nanopart Res 10:89-96

50. Ding S-S, He L, Bian X-W, Tian G (2020) Metal-organic frameworks-based nanozymes for combined cancer therapy. Nano Today 35:100920

51. Jangi SRH, Akhond M (2020) Synthesis and characterization of a novel metal-organic framework called nanosized electroactive quasi-coral-340 (NEQC-340) and its application for constructing a reusable nanozymebased sensor for selective and sensitive glutathione quantification. Microchem J 158:105328

52. Jangi SRH, Akhond M, Absalan G (2020) A field-applicable colorimetric assay for notorious explosive triacetone triperoxide through nanozymecatalyzed irreversible oxidation of 3, 3'-diaminobenzidine. Microchim Acta 187:1-10

53. Antonsson B, Conti F, Ciavatta A, Montessuit S, Lewis S, Martinou I et al (1997) Inhibition of Bax channel-forming activity by Bcl-2. Science 277:370-372

54. Aghajanpour M (2019) Role of BAX, BCL-2, and MICAL-2 genes in esophageal cancer. Res Med 43:170-176

55. Ishida H, Irie K, Itoh T, Furukawa T, Tokunaga O (1997) The prognostic significance of p53 and bcl-2 expression in lung adenocarcinoma and its correlation with ki-67 growth fraction. Cancer Interdiscip Int J Am Cancer Soc 80:1034-1045

56. Ola MS, Nawaz M, Ahsan H (2011) Role of BCl-2 family proteins and caspases in the regulation of apoptosis. Mol Cell Biochem 351:41-58

57. Kroemer $\mathrm{G}$ (1997) The proto-oncogene $\mathrm{BCl}-2$ and its role in regulating apoptosis. Nat Med 3:614-620

58. Lipponen P, Pietiläinen T, Kosma VM, Aaltomaa S, Eskelinen M, Syrjäunen K (1995) Apoptosis suppressing protein bcl-2 is expressed in well-differentiated breast carcinomas with favourable prognosis. J Pathol 177:49-55

59. Saegusa M, Takano Y, Okayasu I (1995) Bcl-2 expression and its association with cell kinetics in human gastric carcinomas and intestinal metaplasia. J Cancer Res Clin Oncol 121:357-363

60. Viale G, Roncalli M, Grimelius L, Graziani D, Wilander E, Johansson H et al (1995) Prognostic value of bcl-2 immunoreactivity in medullary thyroid carcinoma. Hum Pathol 26:945-950

61. Bradbury D, Zhu Y, Russell N (1997) Bcl-2 expression in acute myeloblastic leukaemia: relationship with autonomous growth and CD34 antigen expression. Leuk Lymphoma 24:221-228

62. Lotem J, Sachs L (1993) Regulation by bcl-2, c-myc, and p53 of susceptibility to induction of apoptosis by heat shock and cancer chemotherapy compounds in differentiation-competent and-defective myeloid leukemic cells. Cell Growth Differ: Mol Biol J Am Assoc Cancer Res 4:41-47

63. Deveraux QL, Reed JC (1999) IAP family proteins - suppressors of apoptosis. Genes Dev 13:239-252

64. Sah NK, Khan Z, Khan GJ, Bisen PS (2006) Structural, functional and therapeutic biology of survivin. Cancer Lett 244:164-171

65. Wang J, Zhang B (2018) Bovine serum albumin as a versatile platform for cancer imaging and therapy. Curr Med Chem 25:2938-2953

66. Han J, Wang Q, Zhang Z, Gong T, Sun X (2014) Cationic bovine serum albumin based self-assembled nanoparticles as siRNA delivery vector for treating lung metastatic cancer. Small 10:524-535

67. Kirkin V, Joos S, Zörnig M (2004) The role of Bcl-2 family members in tumorigenesis. Biochim Biophys Acta (BBA) Mol Cell Res 1644:229-249

68. Shadel GS, Horvath TL (2015) Mitochondrial ROS signaling in organismal homeostasis. Cell 163:560-569

69. Ott M, Gogvadze V, Orrenius S, Zhivotovsky B (2007) Mitochondria, oxidative stress and cell death. Apoptosis 12:913-922

70. Skommer J, Brittain T, Raychaudhuri S (2010) BCl-2 inhibits apoptosis by increasing the time-to-death and intrinsic cell-to-cell variations in the mitochondrial pathway of cell death. Apoptosis 15:1223-1233

71. Wang X, Xia J, Wang C, Liu L, Zhu S, Feng W et al (2017) Preparation of novel fluorescent nanocomposites based on au nanoclusters and their application in targeted detection of cancer cells. ACS Appl Mater Interfaces 9:44856-44863

\section{Publisher's Note}

Springer Nature remains neutral with regard to jurisdictional claims in published maps and institutional affiliations.

\section{Submit your manuscript to a SpringerOpen ${ }^{\circ}$ journal and benefit from:}

- Convenient online submission

- Rigorous peer review

- Open access: articles freely available online

- High visibility within the field

Retaining the copyright to your article

Submit your next manuscript at springeropen.com 